\title{
les qualités secondes
}

\author{
Martine Audet
}

John Locke founded his empiricism on a distinction between the primary and secondary qualities of experience. As Jeanne Hersh has it in her overview of Western philosophy, the primary qualities - for example, expanse, solidity and movement - are integral to bodies.'The secondary qualities - for example, colour, smell, sound and taste - come from the way in which bodies act upon our senses; they are produced as the result of the impact of the primary qualities on the perceiving subject.

Les qualités premières sont réelles dans les corps, telles que nous les énumérons : étendue, solidité, mouvement, etc. Les qualités secondes-celles que nous appelons couleurs, odeurs, sons-proviennent, elles, de la manière dont les corps agissent sur nos sens : elles sont engendrées par les qualités premières, mais elles sont élaborées par notre manière de les percevoir.

- Jeanne Hersh, L'Étonnement philosophique, 187, chapitre sur l'empirisme anglais et Locke.

Devant ce qui fut plus belle couleur, faute de lumière, nous dressons la table.

La moitié de détruire réclame des pensées, $\mathrm{du}$ poids pour les objets, les prières.

La moitié, d'abord grinçante puis nécessaire et hardie, prépare l'inquiétude.

Un fruit renferme son temps à venir.

Humides, nos doigts parfument un couteau. 
Des tissus, des croisements composent l'habitacle.

Les mobiles exhibent nos outils disparus.

Éclairerons-nous le haut des images pour $y$ attendre la fascination?

Le plomb des architectes conserve admirablement l'oreille définitive et plus faible.

Le supplice des fenêtres n'est qu'une opposition. 
Longues arêtes et avec les pleurs cette candeur à la main, d'autres bouquets, les fruits:

ce n'est pas fini,

ce n'est pas si fulgurant l'assemblage d'un corps, ses objets précieux...

Des morceaux d'une très pure existence habitent l'étreinte.

Joliment, la doublure les distingue très peu. 
Une question arpente la logique de nos pertes.

Son travail expose les âges de transmission.

Mange-t-elle la laine soyeuse et bien serrée?

Les torsades volubiles, salivaires?

Oh! S'il te plaît! Un oreiller de neige pour ma tête!

L'hiver heureux, très beau, (à l'origine d'un labeur: ses blanches coutures) repose du sens du temps. 
Composante du poème ou de l'objet la perte apprête l'oeil mais aussi l'architecture intérieure, son humilité.

Des miroirs ramassent les oranges.

Plusieurs cadres protègent nos disparitions.

Nous pensons aux coeurs inclinables et vitreux.

L'absence est un lien précisément réfléchi. 